\title{
P266: Risk mapping the circuit of management of anaesthesia in obstetrics parturient to hospital Robert Debre
}

\author{
M Adeoti ${ }^{*}$, J Harthman ${ }^{2}$, V Leroux ${ }^{3}$, A Desroches $^{3}$ \\ From 2nd International Conference on Prevention and Infection Control (ICPIC 2013) \\ Geneva, Switzerland. 25-28 June 2013
}

\section{Introduction}

The optimal functioning of obstetric anesthesia circuit is a key element in the effectiveness of a hospital with a maternity activity since more than $80 \%$ of parturients benefits.

\section{Objectives}

To analyze dangerous situations that may prevent obstetric anesthesia circuit to ensure anesthetic management of the parturient in optimum safety conditions of care.

\section{Methods}

Based on the functional analysis, the preliminary risk analysis (PRA) is constructed in five steps: cutting functional circuit obstetric anesthesia, identification of dangerous events, hierarchy of feared events, ranking functions, establishment of recommendations to reduce or accept the risk.

\section{Results}

The RPA has identified 93 hazardous situations and 178 scenarios which 266 criticality scenarios to criticality $C_{2}$ and 88 to criticality $C_{3}$. They must be action and risk control management of the residual risk for 24 of them. The main causes are related to preventable medical risk (error identification, error in anesthetic management), managerial risk (insufficient personal, non-compliance with instructions) and organizational risk (work overload, insufficient recycling). They are generally human error related to: patient characteristics (clinical status, homonymy, psychological state), the incompleteness of medical records (clinical summary, organization, transmission), the lack of protocol or protocols inadequate (obstetric anesthesia protocols), the failure of safety barriers (consultations and pre-anesthetic visit) and the difficulty of coordination exacerbated by local architecture and buildings.

\section{Conclusion}

The use of this tool for risk management from industry can develop an approach to improving patient safety in obstetric anesthesia.

\section{Competing interests}

None declared.

\section{Author details}

'Central Laboratory, CHU Yopougon, Côte d'Ivoire. 'Hôpital Robert Debré, Paris, France. ${ }^{3}$ Ecole centrale de Paris, Paris, Côte d'Ivoire.

Published: 20 June 2013
doi:10.1186/2047-2994-2-S1-P266
Cite this article as: Adeoti et al: P266: Risk mapping the circuit of management of anaesthesia in obstetrics parturient to hospital Robert Debre. Antimicrobial Resistance and Infection Control 2013 2(Suppl 1):P266.

${ }^{1}$ Central Laboratory, CHU Yopougon, Côte d'Ivoire

Full list of author information is available at the end of the article

(c) 2013 Adeoti et al; licensee BioMed Central Ltd. This is an Open Access article distributed under the terms of the Creative Commons 